\title{
La imaginación cliométrica: una lectura narrativista de Coacción y mercado de E. Tandeter
}

\author{
The cliometric imagination: A narrativist reading of Coercion and \\ Market by E. Tandeter
}

\author{
Nicolás Lavagnino \\ nicolaslavagnino@gmail.com \\ Investigador en el Consejo Nacional de Investigaciones Científicas y Tecnológicas \\ Docente en la Universidad de Buenos Aires (UBA) \\ Puan $480,4^{\circ}$, of. 431 \\ 1406 - Buenos Aires \\ Argentina
}

\section{Resumen}

El presente artículo tiene por objeto interpelar la operación historiográfica, el quién y el cómo de la escritura de la historia, tomando como marco -si bien con algunas reformulaciones y radicalizaciones- la teoría narrativista del discurso historiográfico propuesta por Hayden White en su obra Metahistoria. La propuesta aquí consiste en aplicar el marco narrativista a un soporte textual que representa, hasta cierto punto, el paradigma de la obra historiográfica "profesional" de fines del siglo XX en Argentina: el libro Coacción y mercado. La minería de la plata en el Potosí colonial, 1692-1826, de Enrique Tandeter. El propósito es doble: iluminar algunos aspectos de la operación historiográfica en curso en Coacción [...] y, al mismo tiempo, señalar algunas de las limitaciones del enfoque narrativista tal como White lo presenta.

Hayden White; Narrativa historiográfica; Operación historiográfica.

\begin{abstract}
This article aims to consider the historiographical operation, the question on who and how historiy can be written, taking as its theoretical frame -with some reformulations and developments - the narrativist theory of historiographical discourse proposed by Hayden White in his masterpiece Metahistory. The proposal here is to apply the narrativist framework to a textual base which represents, to some extent, the paradigm of the "professional" historiographical work of the late twentieth century in Argentina: the book Coacción y mercado. La minería de la plata en el Potosí colonial, 1692-1826, by Enrique Tandeter. The purpose is twofold: to illuminate some aspects of the historiographical operation at stake in Coacción [...] and at the same time to point out some of the limitations of whitean narrativist approach.
\end{abstract}

Keywords

Hayden White; Historical narrative; Historiographical operation.

Recibido el: 21/10/2016

Aceptado el: 5/12/2016

* La presente investigación ha contado con el financiamiento de UBA-CONICET (Argentina). 
Todo está horadado como un cascabel, y las Labores antiguas y modernas son tantas que se cruzan por lo interior de sus entrañas como los vacíos de una esponja [...] [y] [...] cada uno trabaja donde puede, siguiendo la Labor en que se metió, sin saber de quién es, ni dónde se halla"

(Correspondencia de Manrique a Sanz apud TANDETER 1992, p. 232).

\section{Revisitando la poética de la historia}

A la hora de considerar la escritura y la operación historiográfica una de las fuentes teóricas habituales en las últimas décadas es Hayden White (WHITE 1992), quien desde Metahistoria en adelante ha postulado una teoría consistente y desafiante a la hora de concebir el discurso de la historia. El objetivo de la recuperación de esta teoría en este artículo es la aplicación de ese marco a un texto que puede ser considerado como uno de los paradigmas de la obra historiográfica "profesional" de fines del siglo XX en Argentina: el libro Coacción y Mercado. La minería de la plata en el Potosí colonial, 1692-1826, de Enrique Tandeter. Los resultados que se proponen con ello van en una doble dirección: por un lado enfocar los rasgos propios de la operación historiográfica en curso en Coacción... y, al mismo tiempo, enfatizar aspectos críticos habitualmente pasados por alto del enfoque narrativista de White.

En cuanto a lo primero es de notar que por su mismo sesgo dentro de la profesión el libro de Tandeter -en sí mismo un modelo de historia serial y cuantitativa basada en primera instancia en el análisis estadístico de fuentespareciera estar en las antípodas de una eventual relectura narrativizante. Encontrar, por tanto, el registro funcional de las operaciones tropológicas y narrativas dentro de la misma operación historiográfica supone un desafío doble. Por un lado implica cuestionar el contrato de lectura establecido en el texto (ECO 1996), que orienta al lector especializado en la decodificación de un texto que supuestamente "no narra", en tanto parece requerir para su inteligibilidad de la operación de otros soportes -en teoría mayormente no narrativos-. La hipótesis aquí es que esos otros soportes lejos de cuestionar la narratividad del texto le dan carnadura.

Por el otro hacer emerger analíticamente este nivel operacional toma prudente distancia de cualquier fácil criticismo que pudiera hacerse a partir de esta emergencia (BARTHES 1971, p. 28): lejos de igualar la operación historiográfica a cualquier visión reduccionista de la literatura, la narración o la ficción, este registro de operaciones permite entender tanto la inteligibilidad de la operación historiográfica como su especificidad y eficacia. En este sentido el registro de operaciones discursivas no es el trampolín desde el cual saltar a un criticismo disciplinar genérico, sino más bien una vía de entrada, entre otras, a las densidades y complejidades operacionales del discurso historiográfico como acto comunicativo y epistémico.

De allí que, en cuanto a lo segundo, el análisis de la complejidad de un texto historiográfico contemporáneo permite iluminar algunos aspectos endebles de la habitual recuperación del marco whiteano (ANKERSMIT 2005; KUUKKANEN 2015; RUNIA 2006). Y esto se lleva a cabo con vistas no a abandonar el marco sino 
paradójicamente con la intención de profundizarlo en cuanto ejercicio analítico. La hipótesis aquí es que la puesta en acto de la teoría permitirá apreciar algunas de las falencias de la misma y, eventualmente, corregirla.

Ahora bien, un rasgo peculiar del marco considerado es que desde las originales postulaciones whiteanas en adelante, por regla general el objeto textual al cual se ha aplicado la teoría (para endosarla o criticarla) ha consistido o bien en las obras de "grandes autores" del pasado disciplinar, mayormente Ios clásicos del siglo XIX -Ranke, Michelet, etc., tal la opción del propio White (WHITE 1978; 1992; KELLNER 1989), o bien se ha trabajado con textos enmarcados en temáticas específicas concernientes a la literatura historiográfica y testimonial sobre el Holocausto y otros acontecimientos "límite" o "modernistas" (FRIEDLANDER 2007; WHITE 1987; 1999).

Ante esto es particularmente notable que el análisis de White se centra en un período clave de la articulación disciplinar, el momento en que las prácticas y saberes propiamente historiográficos se institucionalizan y pretenden realizar una purga de todos aquellos elementos que buscaban mantener abierto figurativamente un pasado para todos aquellos que pretendieran abordarlo. La domesticación del pasado (lo que White denomina su desublimación; WHITE 1987, p. 75 ) es parte inherente de la articulación en el lenguaje ordinario de los historiadores de ciertos protocolos de significación que, para fines del siglo XIX o comienzos del siglo XX ya se encuentran instaurados.

En el curso de las décadas desde Metahistoria en adelante, la estructura de la propuesta whiteana no se ha alterado en lo sustancial, configurando una suerte de ecuación: teoría tropológico-retórico-poética de la historia + análisis puntuales de obras consideradas liminales (ya no clásicos en sentido estricto, pero sí obras que permiten enmarcar los contornos de realidades históricas diversas que desafían los límites disciplinares) + llamamiento disciplinar "crítico". Quizás lo que obras recientes como The practical past (WHITE 2014, p. xiv) permiten entrever es el creciente desencanto de White, la idea de que el Ilamamiento no será atendido, y de allí lo que parece en su última obra una condena in toto a la disciplina por su manifiesta incapacidad o renuencia de aceptar aquello a lo que se la invitaba cuatro décadas atrás.

En suma, si bien el análisis del curso de la obra whiteana y la evaluación de sus méritos y dificultades es materia de otro análisis, por regla general el punto de vista aquí asumido es que la teoría es fértil y válida, pero paradójicamente ha sido notoriamente desatendida por seguidores y detractores de la misma ${ }^{1}$, en la medida en que White se ha enredado en el curso del tiempo en discusiones cada vez más vastas, genéricas $y$, en cierto sentido, empobrecedoras.

Revisitar "la poética de la historia" nos exige concentrarnos en el núcleo de su apuesta conceptual: ¿cómo opera el historiador? ¿Cómo funciona el lenguaje y el discurso historiográfico? ¿Qué peculiaridades y especificidades tiene en el ámbito de la comunicación orientada cognitivamente? Las respuestas que se irán

\footnotetext{
${ }^{1}$ Una notable excepción sería Wulf Kansteiner, en particular su recensión de las dificultades teóricas presentes en White, así como también sus análisis de la obra historiográfica sobre el Holocausto de Saul Friedlander (KANSTEINER 1993; 2009).
} 
desgranando a lo largo de este texto (el historiador opera tropológicamente; el lenguaje historiográfico pone en acto operaciones funcionales específicamente narratológicas; esas operaciones tienen por rasgo distintivo el modo en que se hilvanan en el discurso funciones heterogéneas con la finalidad de atender a las pretensiones epistémicas del "artefacto historiográfico") suponen entonces recuperar el marco whiteano pero, a la vez, para tomar una prudente distancia de White, si es que hemos de evaluar la teoría, considerarla en sus limitaciones y virtudes, con miras a -en algún sentido- radicalizarla en pos de convertirla en un vehículo de análisis relevante del discurso y las operaciones historiográficas.

\section{Operaciones historiográficas}

Publicado en 1992, como resultado según su autor de una labor de veinte años, Coacción y Mercado puede ser considerado como un clásico de la historiografía académica argentina contemporánea desde el momento mismo de su aparición. Traducido rápidamente al inglés y al francés, premiado a repetición en el curso de la primera mitad de la década de los noventa, considerado por muchos un texto capaz de exhibir la profesionalización definitiva en el ámbito de los estudios historiográficos actuales, Coacción y mercado, se presenta así como un artefacto de notable eficacia e impacto en su dominio. En este sentido, para comprender su eficacia es necesario comprender primero al texto en su contexto o, mejor, al sistema historiográfico narrativo forjado por Tandeter en Coacción y mercado en su punto de acoplamiento con el entorno historiográfico, político y social del cual emerge.

\section{a) El texto en su contexto}

Es por demás notorio que en apenas siete párrafos, los que componen la introducción al libro, Tandeter condensa un cúmulo de referencias contextuales que apenas pueden ser reconstruidas por el lector no avisado. En efecto, tratándose de un libro dedicado a un aspecto de la historia económica del mundo andino durante el período colonial, podría esperarse una mención del debate en torno a los modos de producción en América Latina, la polémica entre André Gunder Frank y Rodolfo Puiggrós (FRANK 1965; AAVV 1973), las tesis circulacionistas en boga durante las décadas del sesenta y el setenta, y las discusiones suscitadas por el debate Sweezy-Dobb o Perry Anderson en torno a las formas de transición del feudalismo al capitalismo (ANDERSON 1979).

Ciertamente internarse en este debate apasionante insumiría demasiado tiempo y espacio, además de que ya ha sido estudiado ampliamente. En todo caso conviene precisar en este punto que los primeros artículos de Tandeter están orientados a realizar un balance crítico de estos debates: en 1975 publica un artículo concerniente a la circulación monetaria rioplatense (TANDETER 1975), y un año después dedica un artículo al análisis de la dominación colonial en el cual lo que puede reconocerse es la crítica del autor a lo que considera el defecto principal del entero debate: el predominio de la taxonomía clasificatoria, la generalidad y la vaguedad por sobre la investigación histórica de una realidad histórica concreta y contextualizada (TANDETER 1976, p. 160). 
El complejo contexto de una obra como Coacción y mercado incluye no solamente las vicisitudes teóricas de la época, sino también las políticas y biográficas que llevaron a su autor al exilio durante la Dictadura en la Argentina. Con el retorno de la democracia en 1983, Tandeter volvió al país, donde se consolidó como una figura prominente en la historiografía académica. Su integración disciplinar fue de tal grado que Tandeter es considerado, aún hoy, uno de los integrantes de la camada de historiadores que en la década del 80 encararon cierta idea de la profesionalización y "modernización" requerida por la historiografía en la Argentina. De hecho Coacción y mercado fue publicado en 1992 por la Editorial Sudamericana, en el marco de la colección "Historia y cultura" dirigida por Luis Alberto Romero. A fines de esa década dirigió brevemente el Archivo General de la Nación. Falleció en 2004.

\section{b) Segmentaciones de dominio contrapuestas}

Desde un punto de vista narratológico la forma en la que Tandeter incorpora el contexto denso reconstituido parcialmente en la sección precedente es notable: en apenas un párrafo, el primero de la introducción (TANDETER 1992, p. 9), se encuentra una única referencia a Gunder Frank, a los debates sobre los modos de producción, las diversas renovaciones historiográficas en la Argentina (mencionando a José Luis Romero) y dos notas a pie con referencias bibliográficas de artículos propios en los cuales evalúa las polémicas historiográficas y políticas concernientes al período colonial.

156 Las tribulaciones propias de la investigación ocupan los siguientes tres párrafos. La narración nos muestra a un investigador que va viendo desafiadas sus iniciales intuiciones respecto del objeto que pretende abordar: si el tema inicial era la circulación monetaria en el Río de la Plata en el siglo XVIII (TANDETER 1992, p. 9), las discrepancias de las fuentes lo obligan a inmiscuirse en el problema de la tendencia de largo plazo de la producción de plata en Potosí.

Adicionalmente encuentra un problema con las fuentes y la historiografía que le antecedió: mientras "la historiografía argentina repetía acríticamente" lo que Ricardo Levene había sostenido en sus investigaciones décadas atrás, basándose en un fiscal de la Audiencia de Charcas, Victorián de Villava -de quien Moreno había sido alumno-, Tandeter encontraba en los testimonios de Francisco de Paula Sanz y su asesor Pedro Vicente Cañete una visión radicalmente opuesta (TANDETER 1992, p. 10). El problema radicaba en que mientras Villava había trazado un mapa tétrico de la minería potosina de fines del siglo XVIII, en el marco de una aguda polémica en la que criticaba la legitimidad del trabajo forzado, Paula Sanz y Cañete se contaban entre los instrumentadores de las reformas borbónicas y, como burócratas ilustrados, habían intentado relanzar la minería potosina intensificando la mita en Potosí. Villava, al estar emparentado con Moreno y el ideario emancipador, era tenido por fuente fidedigna a la luz de la interpretación de Levene.

Ciertamente Paula Sanz y Cañete "gozan de muy mala prensa en la historiografía argentina por haber defendido tanto el trabajo forzado indígena, como, más tarde, la posición realista frente a los primeros patriotas de Buenos 
Aires" (ibídem). Sin embargo el punto de arranque de Coacción y mercado es que "entre masas de retóricas y medias verdades" encontramos no en Villava sino en Sanz y Cañete una mejor aproximación a la originalidad y problemática concreta de la minería potosina.

Lo relevante en esta operación es la segmentación de dominio que realiza: los debates previos -incluyendo las muy relevantes contribuciones de autores como Assadourian que informan su recorrido conceptual; ASSADOURIAN 1982son obliteradas completamente, con excepción de una muy breve mención. La intervención de Tandeter aparece como el término faltante en una línea de tres términos precedentes: Levene es asociado a Villava, que a su vez remite a Moreno. Levene, a su turno, representa a "la historiografía argentina". A su vez el develamiento del error de Levene implica la originalidad y pertinencia de la posición historiográfica de Tandeter: lo que se impugna en la página 10, y de allí en más enmarca toda la obra, es el defecto de la asociación metonímica de contigüidad que lleva de Levene, flecha del tiempo atrás, a Villava, pasando por Moreno.

Esto es, en apenas tres párrafos Tandeter ha enmarcado la clave desde la cual se deben leer las otras 313 páginas: el contexto amplio de la operación textual, repleto de tribulaciones, condensaciones de sentido, activaciones políticas, exilios, discusiones políticas presentes, discusiones teórico-metodológicas concernientes a la práctica historiográfica, renovaciones disciplinares y prácticas de profesionalización a la vuelta de la democracia, todo ello está condensado en un primer párrafo que apenas menciona las viejas discusiones, las cuales son consignadas oblicuamente por medio de un par de referencias bibliográficas.

Si la metonimia es un relevo de la implicación causal por mera contigüidad (WHITE 1992, p. 44), el defecto de "la historiografía argentina" es no otra cosa que el mal manejo de las implicaciones causales implícitas en la sucesión metonímica. Romper la metonimia implica remarcar la heterogeneidad de los campos que aquella pretende forzosamente integrar. El desplazamiento conceptual del autor es aquí no otra cosa que la forja de la propia metonimia, el hallazgo entre "masas de retórica y medias verdades" del propio punto de vista y de enunciación, aquel que permite captar "la originalidad de la minería potosina", que no es otra que la originalidad del propio Tandeter frente a una historiografía que, hasta aquí, no ha dejado de repetir a Levene.

\section{c) El fracaso en la larga duración}

La bien ganada fama de Coacción y mercado como obra maestra de la historiografía argentina contemporánea (HERNÁNDEZ 2005; MOUTOUKIAS 1993) puede comenzar a comprenderse a partir de la riqueza de sus instrumentos, dispositivos, operaciones y recursos. Riqueza puesta al servicio de las múltiples capas de sentido que articulan su compleja trama. En efecto, una de las principales dificultades que entraña esta obra es la de llamar la atención con sus recursos mientras aparentemente presenta una línea argumental simple. Y sin embargo el punto de partida de esta lectura de la obra de Tandeter es que en el libro se deslizan no una sino tres tramas, irreductibles entre sí. 
La primera trama es la más general y vasta: se propone presentar un argumento global concerniente al relanzamiento de la producción de plata en Potosí durante el siglo XVIII. La tesis global confronta con una tesis contrapuesta, aquella que pretendía mostrar la larga y declinante tendencia de la minería potosina durante toda la colonia -y de allí el argumento de Villava, que pretendía mostrar no solo la inhumanidad de los trabajos forzados, sino también su ineficiencia desde el punto de vista económico-, desde su auge en el siglo XVI. "Es la historia de esa modesta recuperación la que constituye la materia de este libro" (TANDETER 1992, p. 13), señala Tandeter, y ciertamente no sería exagerado decir que toda esta primera trama se encuentra condensada en el Gráfico 1 de la página 14.

La engañosa simplicidad de la formulación encubre mal la complejidad del tema a tratar, en la medida en que, como veremos, buena parte del libro estará dedicada al estudio acabado de otros tópicos, que difícilmente puedan subsumirse sin rezago en el relato de esa "modesta recuperación".

El problema global en la estructuración de la minería potosina ("su originalidad"), con ser complejos, admiten una fácil visualización, por medio del simple expediente de contrastar dos gráficos, el 2 (TANDETER 1992, p. 66) y el 7 (TANDETER 1992, p. 289). En esas dos páginas se condensa la escenificación global de la primera historia que Coacción y mercado pretende contar. Contrastando ambos cuadros resalta que la "originalidad de la minería potosina" no es otra que la de la triangulación entre salarios, rentas de la propiedad y ganancia del arrendatario en un contexto en que el salario está deprimido artificialmente en virtud de su carácter forzoso por la dominación colonial.

La línea argumental más amplia, la primera trama diremos, de Coacción y Mercado es la de la frustración sistemática de la intención estatal de relanzar la minería de la plata en Potosí. Esta primera trama es el suelo basal sobre la cual se erigen, distintivamente, las otras dos. Se despliega sobre todo en los capítulos primero y quinto, mostrando la tendencia en la larga duración que exhibe el endeble incremento de la producción. En la geografía del texto esta trama se ubica en los extremos, conteniendo y enlazando a las otras, proveyendo el silente pero movedizo telón de fondo contra el cual se recortan los demás movimientos narrativos.

El vehículo de expresión de esta trama es la exposición de los dispositivos cuantitativos asociados a la historia económica, la seriación econométrica y la aplicación de métodos estadísticos al estudio del pasado, un tipo de labor que desde la New Economic History se ha denominado convencionalmente cliometría.

La marca en el orillo de la "modernidad" y disciplinarización de Coacción y Mercado es su uso competente y autorizado de estos recursos. Lejos de discutir leyendas "blancas" o "negras" de la conquista, o generalidades demasiado teóricas acerca de la dominación o el estatuto colonial, la disciplina historiográfica se instancia aquí en un procedimiento autorizado, sancionado como el modo "científico" y apropiado de producir conocimiento. Aunque no versa explícitamente sobre estos dispositivos, indudablemente el texto los muestra, y al mostrarlos los constituye en un objeto de reflexión teórica. 
Ahora bien, esta trama cuantitativamente articulada muestra la frustración sempiterna de las intenciones de los agentes. En su marcación irónica toma distancia del punto de vista de los agentes, mostrando todo aquello que escapaba a su control (WHITE 1992, p. 45; FRYE 1977, p. 294). Narrativamente se construye como una trama cimentada en la ironía, a distancia de las agencias y subjetividades involucradas en procesos de larga duración allende los individuos, basadas en contradicciones estructurales, inintencionadas, circunstancias "queridas por nadie".

\section{d) Subalternidades: los agentes a través de grietas de las instituciones}

Sobre esta base irónica centrada en la frustración estructural en la larga duración de las intenciones y agencias coloniales se constituye, no obstante, el plexo de tramas alternativas que dan carnadura y vida a Coacción y Mercado. En efecto, si la obra en cuestión hubiera consistido meramente en un recuento de las imposibilidades estructurales de largo plazo concernientes a la producción minera en Potosí, el impacto que suscitó habría sido considerablemente menor. Por el contrario, una vez asegurado el marco de larga duración en el cual se encuadra la historia que quiere contar, el texto avanza en una dirección rotundamente opuesta.

El capítulo 2 reconstruye el así llamado "entable de la mita". El "entable" designa en el vocabulario de la época "el modo en que está entablada o dispuesta alguna cosa" (TANDETER 1992, p. 31). La disposición efectiva de la mita, y ése es todo el punto del segundo capítulo, difiere sensiblemente de la legislación presuntamente en curso, precisamente porque a lo largo del siglo que siguió a la conquista se asistió a la progresiva descomposición en jirones de la comunidad andina en la que aquella se aplicaba.

En este contexto es que la obra se bifurca en una doble dirección. Por un lado, y a esto consagraremos esta sub-sección, emprende una fascinante labor de exhibición de las subalternidades en el período colonial. Por el otro reconstruye la intensa faccionalización de las élites, los motivos biográficos, personales, económicos y políticos que la volvieron un intenso remolino de circunstancias.

El "entable" de la mita era el momento en el que esta tensión interna se manifestaba. En este punto emerge la configuración central de esta subtrama: el título del libro, "Coacción y mercado", denota la conjunción de dos términos pertenecientes, en teoría, a campos conceptuales opuestos. Mientras cierta bibliografía, en opinión de Tandeter, sólo se ha concentrado en la situación de los mitayos, lo cierto es que esa institución no agota la complejidad de la minería potosina.

Hasta hace poco tiempo la historiografía subrayaba con exclusividad la importancia de la coacción para definir las intervenciones indígenas en los mercados de trabajo, mercancías y tierras. Pero en los últimos años se han desarrollado estudios que plantean en toda su complejidad las opciones que el sistema colonial, y en particular la demanda mercantil, abría ante grupos e individuos del mundo indígena. La relectura de las fuentes tempranas permite descubrir la rápida percepción por parte de los indígenas de algunos mecanismos del nuevo mercado (TANDETER 1992, p. 100). 
La "nueva perspectiva" obedece a un ejercicio de relectura y, como tal, permite descubrir estratos de sentido pasados por alto originariamente. Los capítulos segundo y tercero exhiben entonces la naturaleza de estas contigüidades no contradictorias entre impulsos coactivos y estímulos de mercado. Nuevamente aquí Tandeter ejerce un papel de labrador de heterogeneidades que desensamblan asociaciones demasiado apresuradas: si era apresurado ligar la suerte de Villava a su recuperación por Levene, o igualmente desacreditar a Sanz y Cañete por ser contra-revolucionarios, también lo es establecer juegos de suma cero entre las dinámicas de la mita y la coacción por un lado, y la lógica del mercado por el otro.

Este estudio de las subalternidades culmina con el largamente aclamado (HERNÁNDEZ 2005, p. 44) capítulo tercero sobre el kajcheo. Si la primera trama había mostrado la imposibilidad de la agencia intencional en el marco de las contradicciones de la larga duración, la segunda trama comienza a exhibir la precariedad y el desmonte de las linealidades demasiado prontas que estructuran la visión de la minería en Potosí. Y si en las páginas 15 y 16 se mentaron ordenadamente los rótulos de las presuntas funciones y divisiones del trabajo en la serie lineal de las labores en el Cerro, el capítulo tres presenta su violenta, caótica y propositiva realidad: terminada la semana laboral, durante los fines de semana, el Cerro es invadido por un ejército irregular de "langostas" (TANDETER 1992, p. 120) que se apropian de piedras y desmontes de alta ley que han "marcado" durante la semana.

Mingas y mitayos durante la semana, se transforman en "bandoleros" que ingresan con o sin consentimiento de propietarios y arrendatarios, para convertir la minería, al decir de Tandeter, "en una actividad popular". Las prácticas de resistencia de los trabajadores durante la semana, "acarreando bazofias inútiles" o laboreando desmontes de baja ley, dejaban intencionalmente para un mejor momento la apropiación particular de las mejores piedras. Los fines de semana eran ese mejor momento, y la actividad de apropiación se denominaba kajcheo.

El kajcheo implicó, entonces, la constitución de una verdadera esfera productiva en la minería potosina, que escapaba al control de los empresarios y aún al de las autoridades. Colectivamente y masivamente indios, mestizos e incluso blancos, protagonizaban la producción como actividad popular (TANDETER 1992, p. 122).

Si en la larga duración las intenciones relevadas se ven frustradas, en el cortísimo plazo tal como se presentan en estos episodios fascinantes que reconstruyen las situaciones concretas de la vida cotidiana en el Potosí del siglo XVIII, el escenario está saturado de agencia y propositividad, resaltada en todos sus cruces, sus contradicciones, contestaciones, ambivalencias y herencias múltiples.

Esta realidad agenciada y a distancia de fáciles generalizaciones es presentada a partir de recursos propiamente narrativos: el estudio de caso del kajcha Antonio Choque y la reconstrucción densa del así llamado "Ruido" de 1751. Lo que se exhibe con ello es hasta qué punto por las grietas institucionales 
coactivas e impersonales se filtran los impulsos agenciados de las subalternidades y propositividades que dan vida a la historia como tal.

\section{e) Élites y redes de relaciones personales}

La última trama de Coacción y Mercado se despliega enmarcada por las otras dos: es la que se desenvuelve al interior de las mismas élites potosinas, en sus eternas y complejas rencillas vinculadas, en lo sustancial, a la separación entre capital mercantil y propiedad minera y entre propiedad y gestión minera. Ésta trama reconstruye las redes de relaciones de parentesco entre diversas familias y grupos amplios que se vuelven visibles en la trama política y económica de Potosí durante el siglo XVIII por medio de un intenso proceso de faccionalización. A la manera de Susan Socolow en su Merchants of Buenos Aires 1778-1810 (SOCOLOW 1978) lo que se reconstruye es una historia de la vida cotidiana del denso entramado colonial en el cual los diversos planos (biográfico, político, económico) se encuentran y se brindan mutua inteligibilidad.

La faccionalización interna encontraba, en última instancia, una contradicción insanable entre los intereses del propietario y los del arrendatario. El margen de uno se contraponía al del otro, en la medida en que el resto de los costos se resistían a la baja o se encontraban ya, como los salarios mitayos, artificialmente deprimidos. Por otro lado la limitación venía dada por la falta de estímulos para asumir riesgos en la labor minera, la cual básicamente consistía en la extracción de "sueltos y desmontes" (CM, p. 17), los cuales eran el resultado de labores previas. Así las cosas la productividad era bajísima, natural corolario de un modo de producción básicamente rentístico y parasitario.

En la construcción de esta trama Tandeter finalmente esboza el aire paradojal de esta situación:

Podemos decir que la inflación de arrendamientos estimuló un aumento de las tareas impuestas a los mitayos que, a su vez, se tradujo en un aumento de la producción potosina durante la segunda mitad del siglo XVIII. De esta manera, el dueño de ingenios con mita, "verdadero zángano de la Azoguería"[...]" contribuyó indirectamente a la reactivación de la minería potosina (TANDETER 1992, p. 194).

Las tres tramas se encuentran, se enlazan y a la vez se distancian en este punto. Los impactos diferenciales de la coacción y del mercado llevan a la articulación de una collatio, en particular mediante la configuración de historias de "vidas paralelas" a lo Plutarco, en la cual lo que se muestra es que con ser supuestamente contradictorias, estas tensiones coactivas y de mercado se presentaban en una y la misma realidad.

El peculiar hallazgo de Coacción y mercado es la inescindible constelación de elementos heterogéneos que compone sus tramas, tanto como sus recursos textuales para "entablar" y disponer las cosas. Tendencias de largo plazo, secuencias disyuntas paralelas que suponen inestables y precarias conjunciones y el denso tramado de la historia de la vida cotidiana se retroalimentan con singular maestría. La multiplicidad de las tramas, lejos 
de conspirar contra el funcionamiento de la obra como un todo, permite comprender su particular eficacia.

Si del conjunto de operaciones historiográficas hubiéramos de optar por una o por otra como "dominante" volviendo subrogantes y derivativas a todas las demás, la potencia del artefacto sería destruida en el acto. Pero para terminar de apreciar esto se hace necesario ponderar la variedad y riqueza de los juegos narratológicos implicados en la constelación inescindible de las heterogéneas tramas que componen Coacción y mercado.

\section{Juegos narratológicos: modos de presentación, tiempo, voces, lecturas}

El ir y venir entre los soportes textuales es parte ineliminable de la vida del discurso. De hecho es esta heterogeneidad la que lo funda (WHITE 1978, p. 4). Entre los elementos presentes en el texto se encuentran aquellos que están vinculados mediante lo que los semióticos llaman sintagmática interna, esto es, "la disposición de las formas escritas vinculadas entre sí y con otras formas dentro del mismo espacio gráfico" (HARRIS 1999, p. 169). Esta operación permite comprender la forma en la que, por ejemplo, un cuadro remite a un mapa, que es recuperado en el texto y luego vuelve a mentarse en forma de gráfico. La funcionalidad del dispositivo depende de esta capacidad para interrelacionar contenidos dispuestos ("entablados") en soportes diversos que puedan ser recuperados en el momento de la lectura.

El análisis de la dispersión en el recurso a estos soportes sintagmáticos internos muestra que éste es más constante en aquellas secciones de la obra en las cuales las tramas agenciadas son inscritas en las tendencias impersonales de la larga duración o cuando se pretende proveer el contexto funcional a través del cual la conducta intencionada de los agentes se inscribe. De allí que la gran mayoría de los cuadros y gráficos se presentan en las proximidades pero por fuera de los extremos de inicio y final de la obra, cuando la trama que se presenta es la más general e impersonal. Cumplen una función mediadora entre la tendencia más general y la línea más narrativa.

El único momento en el que el soporte narrativo adquiere una preponderancia casi total, en detrimento de los soportes vinculados a los diversos recursos gráficos, se da en el tercer capítulo, en ocasión del tratamiento de los mingas y el kajcheo (segunda trama, aspecto "agenciado" de producción minera para el mercado como actividad popular), punto en el cual el modo de presentación predilecto es la recolección testimonial de actas y causas judiciales.

Así, el soporte textual narrativo cobra vigor cada vez que hay que reconstruir los dilemas, intenciones, conflictividades irresolubles y tensiones dinámicas propias de la situación. El contexto amplio en el cual esa dilematicidad se incrusta se confía a un ir y venir entre reconstrucción conceptual, narración breve, gráficos, cuadros y mapas que, en conjunto, anudan la malla semántica en la cual las tramas deben ser leídas.

Los modos de presentación (los recursos textuales empleados en el espacio gráfico), entonces, no son indiferentes a la estructura y dinámica de los contenidos configurados por medio del discurso. Y, a la vez, la trama no es 
algo que se anuda a pesar de estos recursos, sino precisamente a través de ellos. La forma de evitar la recurrente tentación a priorizar un aspecto u otro de las tramas o un recurso en detrimento de otros, es el ir y venir de un recurso al otro a lo largo de todo el texto. En el centro de este flujo y reflujo narrativo se encuentra el episodio de los kajchas, pero la forma en que está "entablado" previene contra cualquier malentendido: es imposible (o sería extremadamente parcial) leer ese episodio con independencia absoluta de los demás.

A estos juegos entre tramas y soportes o modos de presentación, se añaden los juegos con el tiempo y el espacio en la disposición narratológica del discurso historiográfico. El libro pretende tratar sobre la minería potosina entre 1692 y 1826. La temporalidad en sí misma se encuentra notoriamente distorsionada en relación con una eventual comprensión "ingenua" o lineal de la sucesión temporal. Por ejemplo, el análisis de la mita potosina en el segundo capítulo comienza con un cuadro que remite a una visita censal del año 1790 (TANDETER 1992, p. 30), para referir acto seguido al programa administrativo del virrey Toledo en la década de 1570. Luego, sin mayores mediaciones, se inserta una descripción densa del episodio de los mitayos rebeldes de 1801, en lo que constituye un rotundo flash forward en la línea temporal que, a su vez, se vincula oblicuamente en una instancia temporal nunca tratada en detalle en el libro, pero que exige ser mencionada: las rebeliones de la década del 80 .

Estas instancias temporales se iluminan recíprocamente: la rebelión de Tupac Amaru es ininteligible sin la intensificación de la explotación. La cautela reformista posterior es incomprensible sin el antecedente de la rebelión. El ir y venir temporal admite dilaciones, recapitulaciones, puestas en relación por medio de hiatos y líneas de sutura. Una de las líneas de trama exige poner en relación tres gráficos (el 1, el 2 y el 7), que van de 1581 a 1810, luego la línea de la acción narrativa vuelve al período 1790-1793 y luego salta a 1826. Las reversiones, hiatos y alteraciones de la línea temporal se complementan con la función de intensificación temporal: en el centro del texto se encuentra el episodio temporalmente más acentuado de todo el libro: el "ruido de 1751", una serie de acontecimientos puntuales en el cual el texto invierte unas diez páginas.

No solo en los juegos temporales se divisa la operación narratológica. La originalidad de la minería potosina atrajo al investigador tanto como a muchos de sus investigados. En esos raros momentos en los que surge el reflejo entre el autor y aquellos de los que el autor habla, se visibiliza la nota discordante en los juegos con la voz y la forma en la que a partir de esa voz se monta el texto.

$\mathrm{Ha}$ sido muchas veces notado que el uso de pronombres en primera persona o el empleo de ciertos indicadores, deícticos y tiempos verbales suelen estar obliterados en el discurso historiográfico (BARTHES 1971). Estos emergen sin embargo con habitualidad en ciertas ocasiones, y Coacción y Mercado no es una excepción al respecto. La introducción al texto es una de ellas, en las que Tandeter no sólo emplea los recursos discursivos supuestamente ausentes, sino que los utiliza para enmarcar la tesis que va a sostener. "Era evidente que no podía aceptar sin más mis propias cifras", "comprobé pronto que la historiografía argentina repetía acríticamente lo que Ricardo Levene había 
sugerido en sus Investigaciones". "Sanz y Cañete gozan de muy mala prensa en la historiografía argentina [...] sin embargo en sus escritos inéditos, entre masas de retórica y medias verdades, pude empezar a vislumbrar elementos de la realidad socioeconómica potosina". "La originalidad de la minería potosina me atrapó, y me alejé así definitivamente de mi proyecto inicial centrado en la economía colonial rioplatense" (todas las citas, TANDETER 1992, p. 10).

Todas estas enunciaciones establecen desde el inicio mismo el código de lectura y la matriz conceptual desde la cual debe ser leído el texto. Sus tesis, en este punto, son indiscernibles del modo en que son enunciadas, por medio de la aparición de un indubitable yo historiográfico. Pero esta aparición no debilita sino que potencia la voz así articulada.

Con posterioridad, la fortaleza de esta voz autoral no desaparece simplemente porque deje de enunciarse. Una vez inmersos en las múltiples líneas narrativas, el yo historiográfico aparece en la operatoria autoral que lleva de una trama a otra, apelando para ello al manejo autorizado de los recursos múltiples (narrativos, gráficos, por configuración sintagmática) que permiten Ilevar adelante el múltiple decurso que el texto pretende presentar. Esa voz, en suma, aparece de manera eminente como el yo que por medio de la edición y el montaje labora incansablemente su propio "Cerro Rico" de fuentes, testimonios y labores historiográficas previas.

El pasado, al igual que el Cerro, está horadado como un cascabel. La posición de Tandeter es la de aquel que se identifica con el dilema de quién debe "relanzar" los exhaustos estudios sobre el mundo andino. Comprueba inicialmente que buena parte de la historiografía meramente se limita a trabajar "los sueltos y desmontes" que dejara Levene. Las labores antiguas y modernas se entrecruzan, en sus frágiles y presupuestas contigüidades, hasta dejar a los investigadores presos de sus presuposiciones y abstracciones de sentido, sin saber a quién pertenecen ni donde se hallan. La apuesta consiste aquí en la profundización de las vetas de análisis y la sofisticación de los "ingenios", apelando para ello a nuevas tecnologías historiográficas.

Densamente montado, intrincadamente elaborado, Coacción y Mercado articula una voz reconocible, no porque dé cuenta insistentemente de un yo autoral ansioso por hacerse notar, sino porque emerge un estilo reconocible en el modo vanguardista de editar y montar los recursos historiográficos. A partir de Tandeter el entable historiográfico es llevado a un nuevo nivel.

Ciertamente podemos ver estas modalidades cruzadas de prefiguración y configuración que son parte indubitable del texto. La pregunta que surge, inevitablemente, es ¿cómo se lee este texto? La operación lectora requiere aquí el recurso a dos conceptos mayormente ignorados en la discusión narrativista, pero notoriamente presentes en el análisis narratológico: cuáles son los contratos de lectura presupuestos por el texto, y cuáles son las operaciones de concretización requeridas por el mismo (INGARDEN 1998, p. 435). El contrato de lectura orienta en torno al conjunto de operaciones de recepción que deben ser realizadas para emparejar y completar las operaciones de configuración discursiva. Estipular el género del discurso (vg. "policial", "ensayo", "historiografía") presupone una 
marcación definida del tipo de reglas que habrán de regir en ese contrato. Por caso, que el libro versa no solo sobre un dominio tenido por real y efectivo en un tiempo pasado, sino que su expresión en tanto obrar historiográfico sigue las reglas estipuladas por el género, atinentes a la bibliografía, el uso de otros textos, el modo de intercalar las citas, entre otras tantas. Y sin embargo la expresión más importante de esta codificación de género es relativa a la disposición de los elementos gráficos que deben ser recuperados por el lector, en sus concretizaciones, en particular aquellos atinentes a la dispersión sintagmática interna en la cual el texto descansa.

En efecto, la línea narrativa del texto depende de un lector capaz de fluir en una y otra dirección en el curso de la lectura. Debe ser capaz, para captar las tramas, de conectar dos gráficos separados por 223 páginas, de remitir lo visto en un cuadro a lo que se menta en un párrafo dos páginas antes o en una nota a pie varios capítulos adelante. La "seguibilidad" de la narrativa requiere la dislocación y recuperación permanente de lo leído previamente, en pos de retomar ulteriormente la línea del argumento. El tiempo de la acción narrada y el tiempo de la operación lectora divergen notoriamente. Estas son las reglas del género, ciertamente, pero Coacción y Mercado las lleva al paroxismo.

Los bucles o loops de lectura son permanentes en el curso de un abordaje regular del texto que obliga a la recapitulación sucesiva de lo visto previamente. Requieren ir y venir a lo largo del texto, pero también desplazarse oblicuamente atravesando diversos soportes textuales. Una trama emerge de la contrastación narrativa de dos gráficos. Otra de la interrelación entre un mapa, una serie de cuadros y una serie de eventos densamente narrados. La última descansa en la misma heterogeneidad de elementos: cuadros, árboles genealógicos, acontecimientos puntuales, testimonios judiciales, actas, reconstrucciones analíticas de fuentes dispersas. El lector presupuesto en el contrato de lectura es el que puede ejercer las concretizaciones de sentido que dan carnadura al género historiográfico. En este sentido las tramas heterogéneas son sólo uno de los niveles o elementos reconocibles en el sistema narrativo como un todo. Los demás ítems narratológicos son tan relevantes como aquéllas, y sin embargo suelen ser completamente pasados por alto (una excepción a esto, nuevamente, puede verse en KANSTEINER 2009).

\section{Conclusión: la imaginación cliométrica}

El recuento de las operaciones historiográficas y los juegos narratológicos presentes en Coacción y Mercado deberían permitirnos apreciar no solo los estratos de sentido constelados en el texto -y de allí, con suerte, la riqueza de la perspectiva adoptada-, sino también poner en cuestión ciertas limitaciones del esquema narrativista originalmente acuñado por White. Desde Metahistoria en adelante se ha presupuesto que el conjunto de operaciones tropológicas que informan la base figurativa del lenguaje ordinario empleado por los historiadores se manifiesta en la superficie del texto por medio de una serie de compromisos ético-políticos, epistémicos y estéticos que argamasan, conjuntamente, la "poética de la historia". 
Sin embargo en esto la lectura estándar de la teoría se revela demasiado lineal (ANKERSMIT 2001; 2005). Presupone tropos dominantes, tramas unitarias, implicaciones ideológicas prefijadas autoralmente, modos de argumentación formal homogéneos. Las tensiones que se recaban son siempre entre dominancias situadas en planos textuales diversos. Incluso el "estilo" en White surge de las afinidades y aporías resultantes entre caracterizaciones unilineales de conglomerados textuales complejos (WHITE 1992, p. 38-40).

Aquí hemos mostrado, no obstante, tramas múltiples y discordantes, que se vinculan con dinámicas de agenciamiento diferenciales: por caso, la frustración en la larga duración de los impulsos reformistas sugieren una perspectiva irónica y des-subjetivadora. La reconstrucción del entable de la mita monta un escenario trágico signado por lealtades y roles conflictivos, desgarrados por contradicciones insalvables. Esa tragedia es puesta en paralelo sin solución de continuidad con la mirada agenciadora y conciliadora de la producción minera como actividad popular, mostrando una forma heteróclita de reproducción social basada en la contestación subalterna por medio del kajcheo. Ese desafío puede fácilmente mostrarse como protocolarizado siguiendo los patrones propios de la comedia. Finalmente, la reconstrucción de los avatares y lides al interior de las élites de propietarios, arrendatarios y burócratas es performada articulando una auténtica sátira costumbrista, que permite mostrar la saturación de las agencias involucradas en el corto plazo.

Todas estas tramas tampoco re-envían a una implicatura ideológica uniforme, 166 en la medida en que buena parte de las mismas dependen de las concretizaciones en el punto de recepción: ¿el estudio de las subalternidades contra-hegemónicas se sobrepone al estudio impersonal en la larga duración de las tendencias estancadas de la producción, la población y los precios en Potosí? ¿Agenciamiento o ironía? ¿Subalternidades o cliometría? ¿Énfasis en las potencialidades del cambio o prioridad concebida al aspecto paradojal de la sucesión de las tramas? Paradoja en la cual es el auténtico zángano de la minería potosina el que mediante su codicia culmina elevando la producción minera.

En su denso montaje y edición de recursos el texto está estructurado, primeramente, de forma metonímica. Pero es una metonimia contra el trasfondo de otras, que se ejerce irónicamente apelando para ello al recurso de la conjunción de lo aparentemente disyunto: la coacción junto con el mercado. O el mercado por la coacción, y viceversa. Y en la conjunción emerge la transfiguración de las identidades subalternas y el enredo de las perspectivas de la élite. Mitayo en la semana, kajcha sábado y domingo. Arrendatario y propietario. Reformista borbónico y contra-revolucionario. Lo uno por lo otro. Y en el camino, la articulación de un protocolo de exhibición de estas vidas paralelas: la collatio entre el propietario y el arrendatario. Entre las comunidades rurales en el entable de la mita y el kajcheo de los mingas urbanos. Entre la minería mexicana y la potosina.

Lo que podría decirse ante esta densidad operacional es que, paradójicamente, la tropología whiteana es en sí misma demasiado lineal e incompleta como para aprehender el conjunto de las operaciones narratológicas presentes en el discurso historiográfico. Pero este crudo diagnóstico no debería 
llevar a desdeñar la teoría sino a complejizarla, volverla más eficaz. Por ejemplo, Ilamando la atención acerca de los modos de jugar con el tiempo, el espacio, la voz, las concretizaciones y los pactos y modos de lectura en el marco de las reglas que hacen a la eficacia del género como tal.

La dimensión de la sintagmática interna del texto, por ejemplo, ha sido completamente ignorada en el curso de las discusiones en torno a la narrativa. Lo cual es doblemente gravoso: no solo porque hay tramas que pueden instanciarse a través de un recurso eminentemente no narrativo (como la trama impersonal dispuesta a través de la comparación entre dos gráficos separados por más de doscientas páginas que debe ser concretizada temporo-espacialmente en el punto de recepción lectora), sino porque el discurso historiográfico está saturado de montajes no narrativos que dependen extensamente de estos recursos. Diríase que es una de sus modalidades específicas de operación.

Esto no implica que el discurso historiográfico sea eminentemente no narrativo, sino que su narratividad se construye de manera heterogénea apelando a recursos que operan en un nivel más abstracto del mismo. La heterogeneidad está dispuesta o entablada en el punto de emisión y es concretizada por medio de peculiares reglas de lectura.

En última instancia, la inobservancia de todos estos elementos ha derivado en una doble pérdida de interlocución entre teoría de la historia y práctica historiográfica. Por un lado juzgando demasiado limitada la aproximación narrativista, muchos historiadores han lisa y llanamente desatendido la perspectiva como un todo, en la medida en que consideran que sólo es válida para una forma demasiado reducida o anacrónica del discurso historiográfico: las formas de la imaginación histórica propias del siglo XIX, en el punto de encuentro entre la historia acontecimental narrativa y la filosofía especulativa de la historia.

Por el otro, del lado de la teoría, se han admitido de manera demasiado apresurada ciertas consideraciones que estipulan que tras su disciplinarización ha primado una purga de todo gradiente figurativo e imaginativo en el discurso acerca del pasado, configurando un protocolo discursivo marcado por la dessubjetivación autoral, el mandato irónico, la argumentación contextualista, el realismo epistémico y el conformismo disciplinar. A diferencia del siglo XIX, el XX habría carecido por completo de imaginación historiográfica, habiendo sido purgado y "desublimado" su contenido de todo cariz figurativo.

El propósito de este artículo ha sido doble: al mostrar los estratos de sentido tropológico-narratológicamente presentes en Coacción y Mercado, se ha intentado a la vez exhibir parte de aquello que falta elaborar en el diseño de un marco teórico capaz de abordar el discurso de la historia como un acto comunicativo específico. La radicalización narratológica del artefacto teórico mentado debería servir no solo para renovar las discusiones teóricas concernientes al marco disciplinar historiográfico, sino también para permitir relevar, con labores nuevas y ciertamente riesgosas, las formas eminentes de la operación historiográfica. Por ejemplo, los modos en que ha operado la imaginación cliométrica en artefactos densos, ricos, complejos, intrincados y en cascabel como la obra maestra, paradigmática, que es Coacción y Mercado. 


\section{Referencias bibliográficas}

AAVV. Modos de producción en América Latina. México: Siglo XXI, 1973.

ANDERSON, Perry. El estado absolutista. México: Siglo XXI, 1979.

ANKERSMIT, Frank. Sublime Historical Experience. Stanford: Stanford University Press, 2005.

ASSADOURIAN, Carlos. El sistema de la economía colonial. Mercado interno, regiones y espacio económico. Lima, 1982.

BAL, Mieke. Teoría de la narrativa. Madrid: Cátedra, 1985.

BARTHES, Roland. El discurso de la historia. In: SARLO, Beatriz (Comp.). Ensayos estructuralistas. Buenos Aires: CEAL, 1971.

ECO, Umberto. Seis paseos por los bosques narrativos. Barcelona: Lumen, 1996.

FRIEDLANDER, Saul (Ed.). En torno a los límites de la representación. Quilmes: UNQ Editorial, 2007.

FRYE, Northrop. Anatomía de la crítica. Caracas: Monteávila, 1977.

GUNDER FRANK, André. Capitalismo y subdesarrollo en América Latina. Buenos Aires: Signos, 1965.

HARRIS, Roy. Signos de escritura. Barcelona, GEDISA, 1999.

168 HERNÁNDEZ, Juan Luis. La historiografía socio-económica colonial y los debates teóricos metodológicos. Algunas reflexiones. Nuevo Topo, n. 1, p. 33-54, 2005.

INGARDEN, Roman. La obra de arte literaria. Madrid: Taurus, 1998.

KANSTEINER, Wulf. Hayden White's Critique of the Writing of History. History and Theory, v. 32, n. 3, p. 273-295, 1993.

Success, Truth, and Modernism in Holocaust Historiography: Reading Saul Friedländer Thirty-Five Years after the Publication of Metahistory. History and Theory, v. 47, p. 25-53, 2009.

KELLNER, Hans. Language and Historical Representation. Madison, Wisconsin: University of Wisconsin Press, 1989.

KUUKKANEN, Jouni-Matti. Postnarrativist Philosophy of Historiography. Londres: Palgrave McMillan, 2015.

MOUTOUKIAS, Zacarías. "Enrique Tándeter, Coacción y mercado" (reseña bibliográfica). Revista de Historia Económica, v. XI, n. 1, p. 213-216, 1993.

RUNIA, Eelco. Presence. History and Theory, v. 45, 2006, p. 1-29, 2006.

SOCOLOW, Susan. The Merchants of Buenos Aires 1778-1810. Family and Commerce. Cambridge: Cambridge University Press, 1978. 
TANDETER, Enrique. El papel de la moneda macuquina en la circulación monetaria rioplatense. Cuadernos de Numismática, v. IV, n. 14, 1975. . Sobre el análisis de la dominación colonial. Desarrollo económico, $v$. 16, n. 61, p. 151-160, 1976.

. Coacción y mercado. La minería de la plata en el Potosí colonial, 1692-1826. Buenos Aires: Sudamericana, 1992.

WHITE, Hayden. Tropics of discourse, Essays in Cultural Criticism, Baltimore: Johns Hopkins University Press, 1978.

. The content of the form. Narrative Discourse and Historical Representation. Baltimore: Johns Hopkins University Press, 1987.

. Metahistoria. La imaginación histórica en la Europa del siglo XIX. México: Fondo de Cultura Económica, 1992 [1973].

Figural Realism. Baltimore: Johns Hopkins University Press, 1999.

The Practical Past. Evanston, Illinois: Northwestern University Press, 2014. 